\title{
Simulating Land Use Change in the Seoul Metropolitan Area after Greenbelt Elimination Using the SLEUTH Model
}

\author{
Soyoung Park, ${ }^{1}$ Keith C. Clarke, ${ }^{2}$ Chuluong Choi, ${ }^{3}$ and Jinsoo Kim ${ }^{3}$ \\ ${ }^{1}$ BK21 Plus Project of the Graduate School of Earth Environmental Hazards System, Pukyong National University, 45 Yongso-ro, \\ Nam-gu, Busan 48513, Republic of Korea \\ ${ }^{2}$ Department of Geography, 1720 Ellison Hall, University of California, Santa Barbara, Santa Barbara, CA 93106-4060, USA \\ ${ }^{3}$ Department of Spatial Information Engineering, Pukyong National University, 45 Yongso-ro, Nam-gu, Busan 48513, Republic of Korea
}

Correspondence should be addressed to Jinsoo Kim; jinsookim@pknu.ac.kr

Received 24 April 2017; Revised 9 July 2017; Accepted 25 July 2017; Published 28 September 2017

Academic Editor: Hyung-Sup Jung

Copyright (C) 2017 Soyoung Park et al. This is an open access article distributed under the Creative Commons Attribution License, which permits unrestricted use, distribution, and reproduction in any medium, provided the original work is properly cited.

\begin{abstract}
The aim of this study was to analyze the effect of a policy aimed at the removal of a greenbelt on future urban growth. The SLEUTH model was applied to the Seoul Metropolitan Area, South Korea, to predict urban growth under three different greenbelt removal scenarios. The accuracy of the model was verified using historical data with ROC and Kappa statistics of 82.6 and $76.3 \%$, indicating reasonable accuracy. In the scenarios, suburban development grew in proportion to the degree of reduction of the greenbelt. In two of the scenarios, suburban cities in the inner part of the greenbelt were integrated into the metropolitan area. In scenario 3 , a complete removal of the greenbelt resulted in the highest rate of projected urban development. The Seoul Metropolitan Area is under continuous developmental pressure, and the sacrifice of a certain amount of protected land to satisfy this demand may be inevitable. Accordingly, effective urban growth management is necessary to promote ecofriendly and sustainable development in formerly protected areas and to strengthen protection in the areas that will remain protected. The model outputs will be used by the government and policy makers to devise a more flexible and sustainable urban growth management policy.
\end{abstract}

\section{Introduction}

The second half of the twentieth and start of the twenty-first centuries have seen rates of urbanization that are unprecedented in human history, primarily in the developing world $[1,2]$. More than half of the world's population, 3.5 billion people, now live in urban areas, whereas, in 1800, the figure was only about 3\% [3]. By 2030, approximately 5 billion people are expected to reside in urban areas, accounting for $60 \%$ of the planet's anticipated 8.3 billion people [4]. Population increase and urbanization result in significant changes to landscapes and environments and can cause a variety of socioeconomic and ecological problems such as air and water pollution, degradation of cultivated land due to urban sprawl, alteration of hydrological characteristics, reduction of biodiversity, transportation congestion, and housing shortages [5-7]. These issues have a range of effects from larger concerns such as global climate change down to the achievement of local sustainable development [8].
Against this background, many policies and regulations have been designed and implemented to control or mitigate urban sprawl. As a result, urban containment policies have emerged as a popular means of reducing sprawl and preserving farmland [9]. Urban containment policies have included urban growth boundaries, urban service boundaries, and greenbelts, each intended to contain specified types of future urban development within predefined boundaries, to curb urban sprawl, and to encourage infill development [10]. Among urban containment policies, the greenbelt, which is a physical area of protected open space surrounding a city or metropolitan area, is the most restrictive form, because development is strictly regulated or prohibited within the greenbelt itself [11].

Since the 1960s, Korea has experienced many urban problems due to its rapid urbanization and industrialization. Beginning in 1971 and through the early 1970s, the Korean government designated eight greenbelts $\left(5397 \mathrm{~km}^{2}, 5.4 \%\right.$ of 
the nation's territory) in 14 areas surrounding cities to prevent disorganized urbanization and to preserve the natural environment. Korea's greenbelt policy has been shown to be the most successful urban containment policy among the policies employed by Asian countries [12]. However, Korea's greenbelt policy has been criticized due to its associated problems such as growing land demand, property rights of landowners, and the rise in commuting distances. As a result, greenbelts in some regions have been eliminated in some cities, and existing greenbelts in other regions are now being gradually removed according to the national Urban Master Plan. As the elimination of the ban on development within the greenbelts is considered, it is important to evaluate the anticipated urban growth so as to establish a new urban growth management policy that will retain the original goals of greenbelts. Greenbelts are intended to check sprawl, prevent the merging of built-up areas, protect the countryside, including its cultural and historic significance, and encourage redevelopment within cities. Their positive goals are the provision of access to open space for urban dwellers, the retention of attractive landscapes, and the conservation of nature, agriculture, and forestry.

In the last few decades, land use change models have played an important role in understanding the causes, mechanisms, and consequences of land use dynamics. The models have provided an opportunity to explore and evaluate land use policies and have helped to visualize alternative futures [13]. Among different types of land use change models, the cellular automaton (CA) model is the most impressive, due to its flexibility and simplicity in model application as well as its compatibility with remote sensing data and geographic information systems. To date, many researchers have developed CA-based models, including iCity [14], DINAMICA [15], CLUE-S [16], SIMLAND [17], LEAM [18], and SLEUTH [19]. Among these, the SLEUTH model, a modified CA model, resolves constraints such as spatial homogeneity, uniformity of neighborhood interactions, and the universal transition functions of the classic CA model [20, 21]. Moreover, the SLEUTH model explores the influences of different spatial considerations in land use planning. A flexible environment is provided in which alternative scenarios are applied [22]. Therefore, we selected the SLEUTH model for use in this study.

A prior study assumed that compact development would lead to the full elimination of the greenbelt zone and more compact future urban growth [23]. Under this assumption, we analyzed future urban growth to overcome land shortages due to urban development. The present study aimed to evaluate the effect of planned greenbelt removal on future urban growth and to perform a functional assessment of the greenbelt. Therefore, the primary steps and contributions of this study were to (1) construct input data for the SLEUTH model using various thematic maps, (2) analyze the areas eliminated from the greenbelt zone through environmental assessment, and (3) establish three different scenarios based on the degree of elimination. Following calibration and validation of the model, future land use responses to each scenario were analyzed and compared.

\section{Study Area}

The regional scope of this study comprises the Seoul Metropolitan Area (SMA) in South Korea, which includes Seoul, Incheon, and Gyeonggi-do. The target area is $6022 \mathrm{~km}^{2}$ (Figure 1) and excludes some parts of Incheon and Gyeonggido. In Korea, urbanization is divided into the middle period and later period, before and after 1990, respectively. In the later urbanization period, population growth began to be higher in nearby cities than in large cities, and the local government system was established, decentralizing urban society and beginning the structural qualitative changes that accompany urbanization [24]. Rapid urbanization occurred during the middle urbanization period, which can lead to overestimations in model predictions. Thus, we set the calibration period as 1990-2010 and predicted the urban growth of SMA areas for 2020.

The greenbelt zone in the SMA is $1416 \mathrm{~km}^{2}$, which accounts for $40 \%$ of the total area of greenbelt zones of Korea and is 2.5 times the total area of Seoul. Currently, illegal construction occurs throughout the area, due to the high pressure of development within the greenbelt zone. This has caused damage to green space and is a hindrance to the city environment. As a result, the "2020 Metropolitan CityRegion Planning in the National Land Use Planning Law" was established by Korea's Ministry of Land, Infrastructure, and Transport (MLIT), Seoul, Incheon, and Gyeonggi-do. It was decided to gradually eliminate certain parts of the greenbelt by 2020 to create working-class residential areas and to stimulate the regional economy.

In addition, although the population growth rate of SMA has been regulated since 1997, 49\% of South Korea's population live within its boundaries. According to the future population projection by Korea's National Statistical Office, the population of SMA will reach 25.1 million by 2040, and more than $51 \%$ of Korea's population will live within its borders.

SMA is under urban development pressure due to continuous population growth and industrialization. Significant changes in urban land use are expected in districts where restrictions on development are lifted.

\section{Data and Methods}

3.1. SLEUTH Model. The SLEUTH model is the improved version of the Clarke Cellular Automaton Urban Growth Model, originally developed by Clarke and colleagues [19]. The acronym SLEUTH refers to the model's data input requirements: slope, land use, exclusion zone, urban, transportation, and hillshade. The model runs on UNIX or UNIXbased operating systems and is composed of the urban growth model (UGM) and the deltatron land use change model (DLM); the latter is optional [25].

SLEUTH simulates four types of urban land use change: spontaneous growth, addition of new spreading-centers, edge growth, and road-influenced growth. These four growth types are applied sequentially during each growth cycle or year and are controlled through the interactions of five growth coefficients: diffusion, breed, spread, road gravity, and slope [26]. 


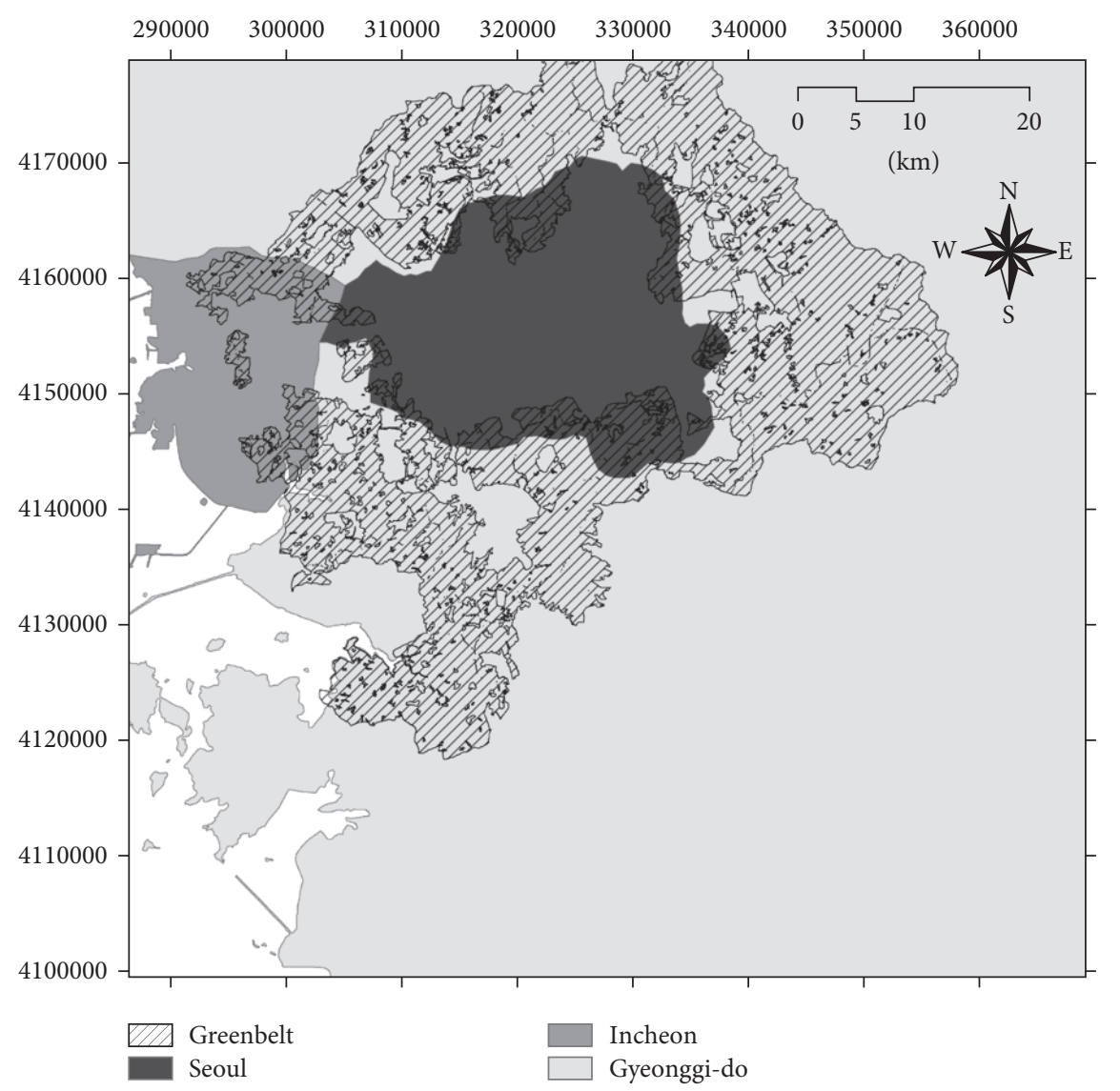

(a)

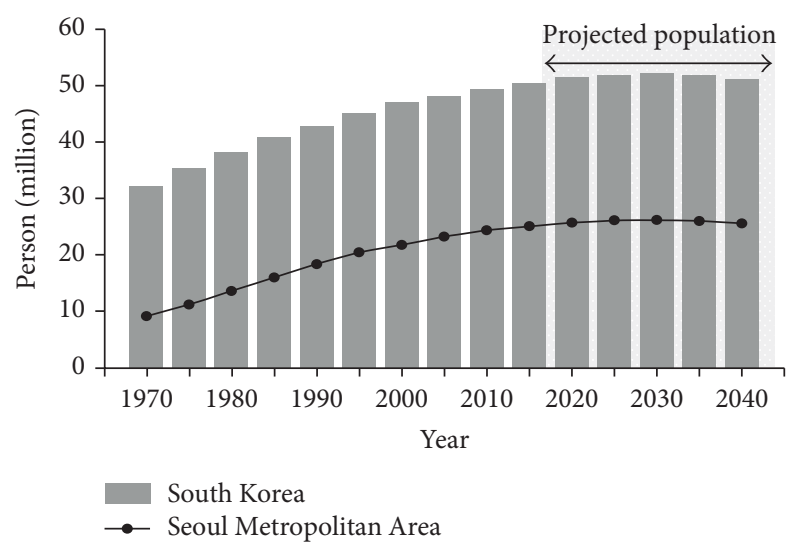

(b)

\begin{tabular}{lccc}
\hline$\left(\right.$ Unit: $\left.^{2} \mathrm{~km}^{2}\right)$ & Designation & Elimination & Existence \\
\hline $\mathrm{SMA}^{\mathrm{a}}$ & 1,567 & 152 & 1,415 \\
Seoul & 168 & 17 & 151 \\
Inchon & 97 & 8 & 88 \\
$\quad$ Gyeonggi-do & 1,302 & 127 & 1,175 \\
Other regions & 2,727 & 280 & 2,447 \\
Total & 5,397 & 1,536 & 3,862 \\
\hline
\end{tabular}

(c)

Figure 1: Status of the Seoul Metropolitan Area (SMA): (a) location of the study area and the greenbelt, (b) transition of the populations of South Korea and SMA from 1970 to 2040, and (c) current status of the greenbelt as of December, 2014. Population and greenbelt data $\left(\mathrm{km}^{2}\right)$ were obtained from the homepage of the Korean National Statistical Office. ${ }^{a}$ Seoul Metropolitan Area.

Values for each dimensionless coefficient range from 0 to 100 , with higher values indicating greater relative importance [25]. Table 1 shows the relationships between growth types and coefficients. Appropriate coefficient values are identified by the user via an automated calibration process in which various combinations of coefficient values are tested, usually through a brute force method, and the best performing coefficient set is selected [27]. Additionally, SLEUTH has a self-modification rule that allows the coefficients to change according to the urban growth rate. With self-modification, SLEUTH can produce linear, exponential, or S-shaped urban growth curves, which can realistically reflect different rates of urban sprawl $[19,28]$. Figure 2 shows the general structure of the model [13].

SLEUTH 3.0 under Cygwin using a GNU compiler (GNU Compiler Collection) was downloaded and compiled. As 
TABLE 1: Relationship between growth types and growth parameters.

\begin{tabular}{lll}
\hline Growth type & Controlling coefficients & Description \\
\hline Spontaneous & Diffusion & Simulates random urbanization of land \\
New spreading center & Breed & $\begin{array}{l}\text { Simulates establishment of new urban growth centers } \\
\text { Edge }\end{array}$ \\
Spread, slope & $\begin{array}{l}\text { Simulates outward expansion and infilling of existing urban } \\
\text { areas }\end{array}$ \\
Road-influenced & $\begin{array}{l}\text { Road gravity, diffusion, } \\
\text { breed, slope }\end{array}$ & $\begin{array}{l}\text { Simulates newly urbanized cell growth along transportation } \\
\text { networks }\end{array}$ \\
\hline
\end{tabular}

Source: Tan et al. (2009).

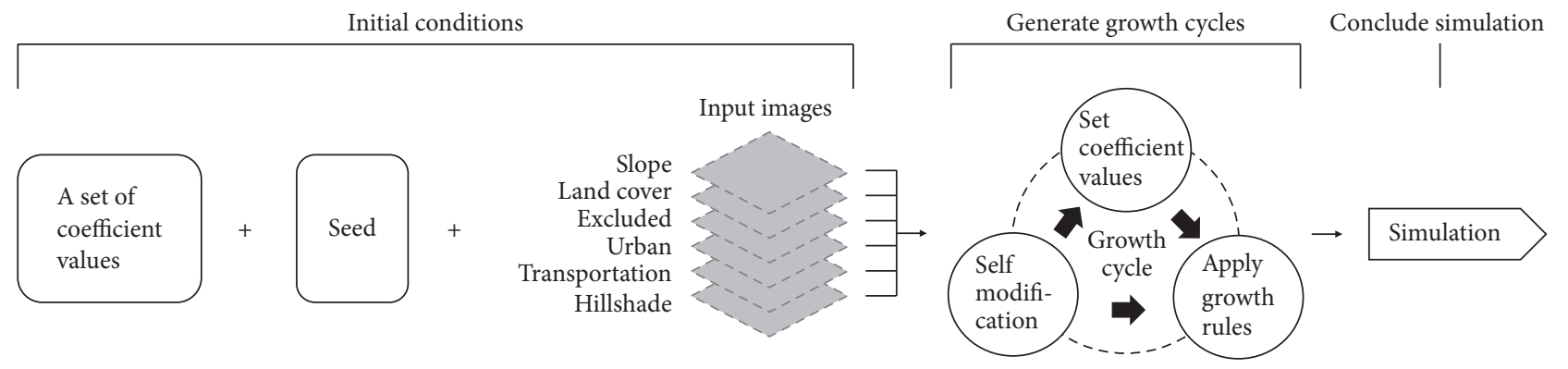

FIgURE 2: Structure of the SLEUTH model.

recommended, the model was run first in test mode to ensure that it functioned correctly.

3.2. Input Data Preparation. Generally, to operate SLEUTH, a minimum of four historical urban extents, two land use maps for different time periods, and two or more transportation networks are required. Except for topographic slopes, a hillshade layer and excluded areas are required, with the hillshade layer used for visualization. If only urban growth is to be estimated, land use data is not necessary.

3.2.1. Land Cover, Slope, and Transportation Inputs. Land cover maps of 1990, 1995, 2000, and 2010 acquired from the Water Management Information System (WMIS) of Korea's MLIT and Korea's Ministry of Environment (ME) were used in this study. Land cover maps were converted into Boolean urban/nonurban layers and used as the urban layer to depict the profile of SMA dynamics since 1990.

Slope and hillshade layers were obtained using a 30m Advanced Spaceborne Thermal Emission and Reflection Radiometer (ASTER) Global Digital Elevation Map (GDEM). The slope layer was transformed to percent slope, as required by the model. The hillshade layer was used as a background image for the model image and animation output.

For transportation network layers, information on the 2005 transportation network at a scale of 1:25,000 was provided by the Intelligent Transportation Systems-Standard Nodes Link (ITSSNL) of Korea's National Transport Information Center (NTIC). In addition to the transportation network of 2005, a 1:25,000 digital topographic map was used to establish the transportation network of 2000. Because different types of roads attract urban growth in different ways [29], pixel values were assigned weights according to the degree of development of the transportation network layer. Expressways, urban expressways including national and provincial highways, local primary roads, and others including local roads and those reserved for special use were assigned values of $100,75,50$, and 25 , respectively. Higher values represent roads with a relatively high tendency to attract urban growth.

3.2.2. Excluded Layers. Excluded layers are the areas excluded from urbanization based on physical and legislative restrictions. Locations where urban development was considered impossible were assigned a value of 100 or greater and locations that were available for urban development were assigned a value of zero. A value of 50 was assigned to indicate a neutral weighting for development. Excluded layers were produced using GDEM, an ecoenvironmental conservation value assessment map (ECVAM), water bodies, the greenbelt zone, and the zone eliminated from the greenbelt. The ECVAM were graded from 1 to 5, using an overlapping analysis for 57 variables related to law and 8 variables related to environment, respectively, with grade 1 indicating the highest conservation value.

The first excluded layer represents the continuous existence of physical and legislative resistance without any change. Areas with a gradient of over 25 degrees and altitude over 100-m were extracted using GDEM and were assigned a value of 100 (excluded). The first grade areas of ECVAM were assigned a value of 100 , the second grade areas were assigned a value of 75, and the third grade areas were assigned a value of 50 . Bodies of water were extracted using the 2010 land cover map and were assigned a value of 100 . This layer was used for scenario 1 .

The second excluded layer represents the full elimination of the greenbelt. The greenbelt zone was assigned a value of 0 , which means that it was fully available for urban 
TABLE 2: Input data set for the SLEUTH model.

\begin{tabular}{|c|c|c|c|c|}
\hline Input layer & Source & Scale & Format & Date \\
\hline \multirow{2}{*}{ Land use, urban } & WAMIS $^{\mathrm{a}}$ & $1: 50,000$ & Raster & $1990,1995,2000$ \\
\hline & $\mathrm{ME}^{\mathrm{b}}$ & $1: 50,000$ & Raster & 2010 \\
\hline Slope, hillshade & ASTER GDEM $^{c}$ & - & Raster & 2011 \\
\hline \multirow{2}{*}{ Transportation } & Topographic digital map & $1: 25,000$ & Vector & 2000 \\
\hline & ITSSNL $^{\mathrm{d}}$ & $1: 25,000$ & Vector & 2005 \\
\hline \multirow{5}{*}{ Excluded } & ASTER GDEM & - & Raster & 2011 \\
\hline & ECVAM $^{\mathrm{e}}$ & $1: 25000$ & Raster & 2010 \\
\hline & Water bodies & $1: 50,000$ & Raster & 2010 \\
\hline & Greenbelt zone & - & Vector & 2010 \\
\hline & Eliminated zone & - & Raster & 2010 \\
\hline
\end{tabular}

${ }^{a}$ Water Management Information System; ${ }^{b}$ Ministry of Environment in Korea; ${ }^{c}$ Advanced Spaceborne Thermal Emission and Reflection Radiometer Global Digital Elevation Map; ${ }^{\mathrm{d}}$ Intelligent Transportation Systems-Standard Nodes Link; ${ }^{\mathrm{e}}$ Ecoenvironmental Conservation Value Assessment Map.

development. The assigned values for slope, elevation, ecoenvironmental conservation areas, and water bodies were the same as those of the first excluded layer. This layer was used for scenario 2 .

The third excluded layer represents the partial elimination of the greenbelt. The first grade areas of ECVAM were assigned a value of 100; the second grade areas were assigned a value of 75; and the third grade areas were assigned a value of 50. The eliminated greenbelt zone was assigned a value of 0 . The assigned values for slope, elevation, legal conservation areas, and water bodies were the same as those of the first excluded layer. This layer was used for scenario 3.

All input data layers were clipped to the same spatial extent as the study area and converted into 100-m-resolution raster grids. The dimensions of the grids were 829 columns by 797 rows. All input data layers were geometrically rectified at the source to the Universal Transverse Mercator (UTM) Zone 52N 1984 World Geodetic System (WGS 84) and then converted into graphic interchange format (GIF) with a grayscale palette and naming convention, as required by the model. Table 2 and Figure 3 show the resulting input data sets for SLEUTH.

3.3. Elimination of the Greenbelt. The areas of lower conservation value within the greenbelt zone were eliminated through environmental assessment by the "2020 Metropolitan CityRegion Planning in the National Land Use Planning Law.” The environmental assessment provided a mechanism to evaluate high and low conservation value using overlapping analysis for six factors: elevation, slope, flora, agricultural suitability, forest suitability, and water quality. All items were graded by setting standards (Table 3 ).

Elevation and slope were classified and graded using the GDEM. Flora was graded by the age and origin of the forest using a forest map, which was acquired from Korea's Forest Geographic Information System from the Korea Forest Service (KFS). Agricultural suitability was graded using the grade of agricultural suitability, the agriculture development region, and the arable land rearrangement region. The grade of agricultural suitability was identified from a detailed soil map, which was acquired from the Korean Soil Information System of the Rural Development Administration.

Water quality consisted of four specific items. The four specific items were scored according to standards per item and were combined (Table 4). Buildings were extracted using a topographic digital map and the index of the water quality was calculated by the ratio of building to watershed size. The distance from the intake station was scored using the location of the intake station, which was identified from the 2010 waterworks statistics. The permissible emission standards for wastewater and the environmental standard for water quality were scored according to values provided by the "Water Quality Conservation Act.”

Finally, the total grade was classified with an overlapping analysis for the four items. The eliminated zones were selected as third, fourth, and fifth grade, which covered more than $0.2 \mathrm{~km}^{2}$. However, the areas where significant environmental damage and development of conurbations were expected were excluded from the eliminated zone by the "2020 Metropolitan City-Region Planning in the National Land Use Planning Law." This planning defined these areas as "mountain areas with an altitude over $70 \mathrm{~m}$ " and "areas located within a $5 \mathrm{~km}$ zone inside the greenbelt boundary," respectively. The total area of the eliminated zone was $11,024 \mathrm{~km}^{2}$.

3.4. Model Calibration. The success of a model mostly depends on the calibration process, which is used to narrow down the values resulting from the model to reflect local characteristics [30]. In this phase, the model is calibrated by fitting simulated data to real historical data collected from the study area. The purpose of the calibration phase is to derive a set of values for the coefficients that can effectively model growth during the historical time period, in this case, from 1990 to 2010 [25].

The calibration process is divided into three phases (coarse, fine, and final) in which the coefficient space is extensively explored through a number of sequential Monte Carlo iterations employing possible combinations of 


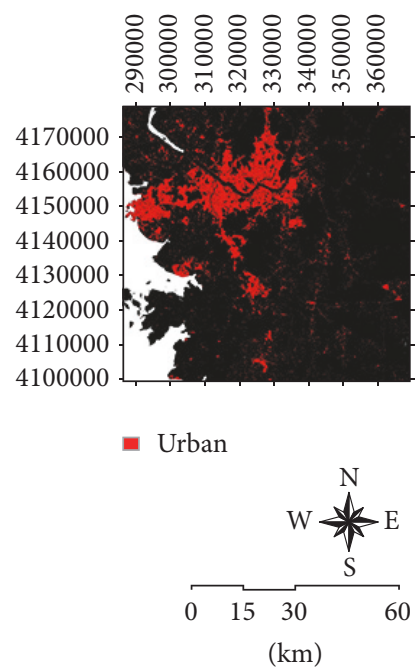

(a)

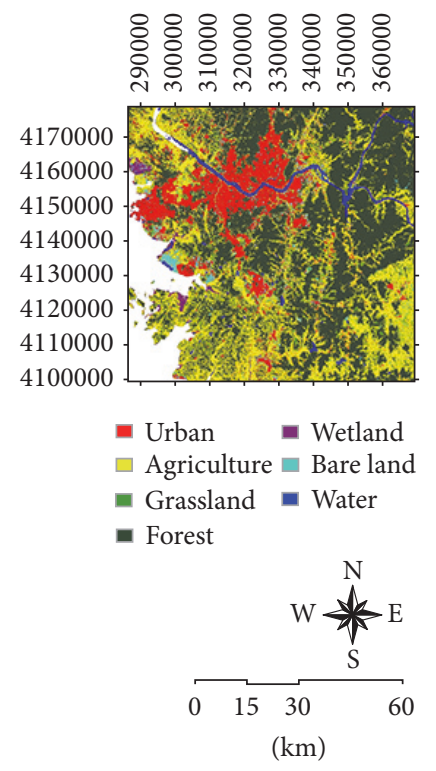

(e)

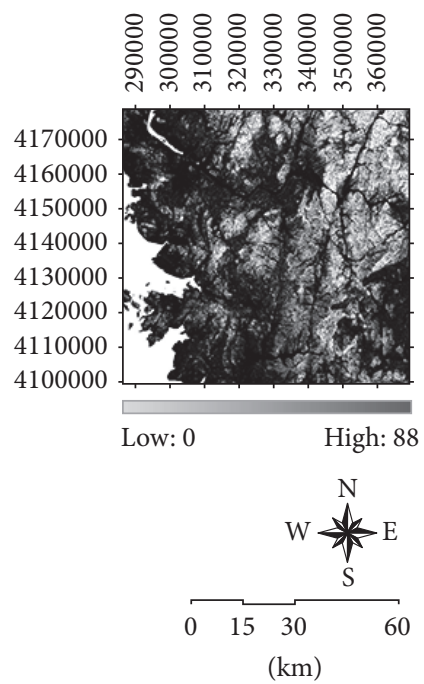

$(\mathrm{km})$
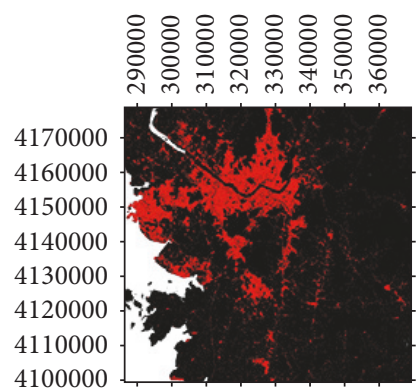

E Urban

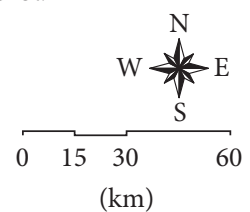

(b)
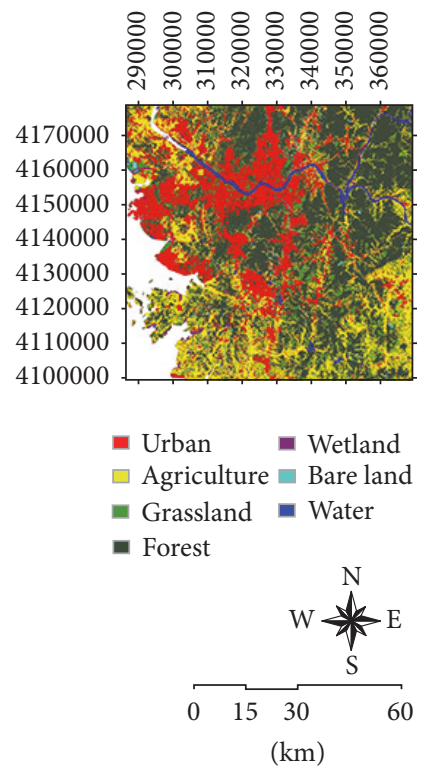

(f)

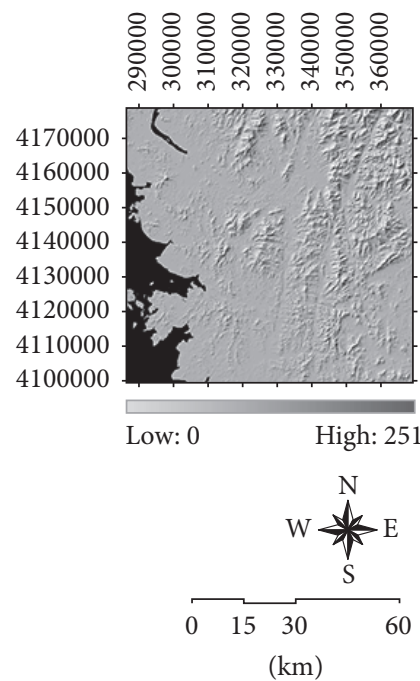

¿̊ \&
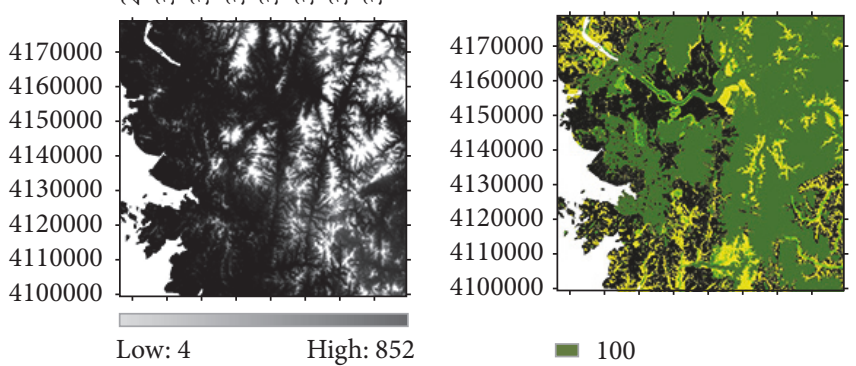

$$
\begin{aligned}
& \square \\
& \square \quad 100 \\
& \square \\
& \square 50
\end{aligned}
$$
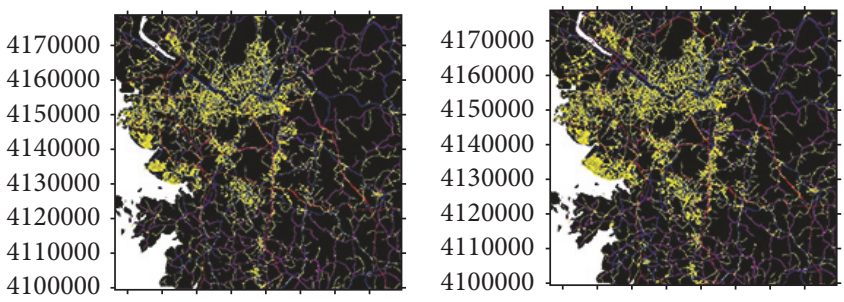

$\square 25$ (others)

- 50 (local road)

- 75 (urban expressway)

- 100 (expressway)

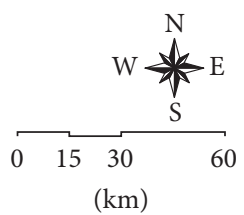

(h)

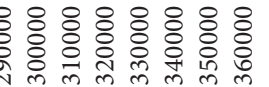

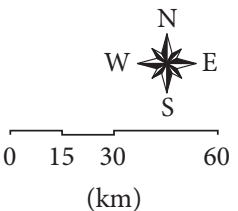




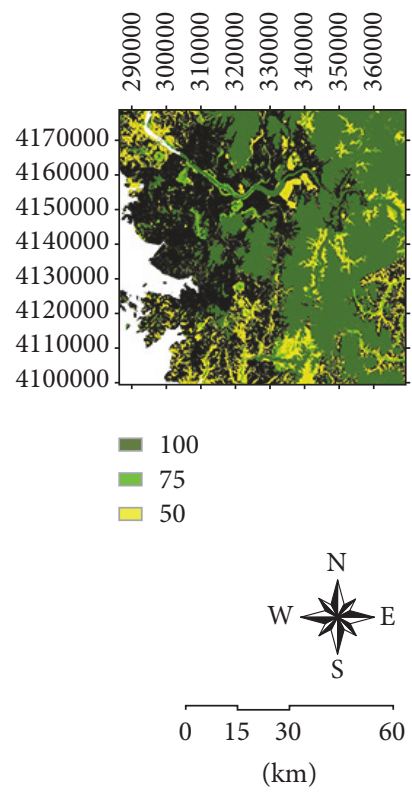

$(\mathrm{m})$
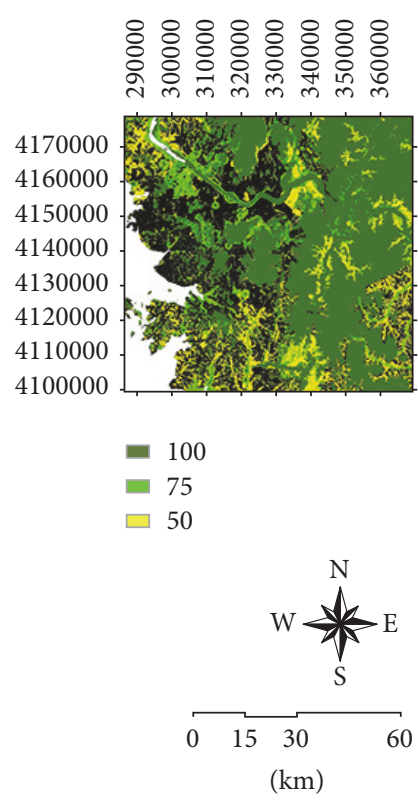

(n)

FiguRE 3: Input data set used in this study: (a) urban area in 1990, (b) urban area in 1995, (c) urban area in 2000, (d) urban area in 2010, (e) land use in 1990, (f) land use in 2010, (g) transportation network in 2000, (h) transportation network in 2005, (i) slope, (j) hillshade, (k) elevation, (l) first excluded layer, (m) second excluded layer, and (n) third excluded layer.

coefficients [22]. During each step of the calibration, various goodness-of-fit parameters were computed having a value range of 0.0 to 1.0 , with 1 being a perfect fit [13].

All indices were combined and sorted in descending order based on the optimal SLEUTH metric (OSM), which is the product of the compare, population, edges, clusters, slope, $X$-mean, and $Y$-mean metrics (Table 5). The OSM was developed to produce robust and comparable results for SLEUTH calibration [31]. After each calibration phase, the parameter set resulting in the best OSM values determines the range of values used in the subsequent phase of calibration [28].

Finally, by using the best set of derived coefficients after the three phases of calibration, the model was executed to simulate the historical data set [22]. Once calibrated, the ending coefficient values were determined and used to begin forecasting.

3.5. Model Prediction. Three different methods have been used to predict urban growth under different scenarios: evaluation of the change in the growth coefficients, manipulation of self-organization constraints, and investigation of the different levels of protection values in the excluded layer [32]. The third method was used to predict urban growth to 2020 . Each of the scenarios corresponded to a unique excluded layer.

Xiang and Clarke [33] suggested three criteria, including plausible unexpectedness, informational vividness, and cognitively ergonomic design for every set of acceptable scenarios. The design of scenarios should be based on these three criteria and should be strongly linked to the current existing concerns of the policymakers of the region addressing the key questions as well as the historical urban growth trend [34]. The three simple scenarios were established to provide a comprehensible and alternative context for city managers and decision-makers.

The first is the maintenance scenario, which aims to predict future urban growth under the continuation of the historical trend. The physical and legislative resistance in the study area was sustained without changes. The second is the elimination scenario, which aims to predict urban growth if the greenbelt zone were completely eliminated. The result of this scenario could be used to identify the beneficial and adverse effects of the greenbelt in comparison to other scenarios. The third is the controlled elimination scenario, which aims to predict urban growth if the greenbelt was partially eliminated by the "2020 Metropolitan CityRegion Planning in the National Land Use Planning Law." The goal of this planning law is environmental conservation and ecofriendly urban development. According to this goal, areas of lower conservation value would be eliminated and developed in an ecofriendly manner to minimize environmental damage. In addition, the areas near Seoul would be protected from development to avoid the creation of continuous conurbations. The results of this scenario could be used to identify how greenbelt management policy would be affected and how it could be improved to compensate for the defects of the current policy.

\section{Results}

4.1. Model Calibration. The model was calibrated according to the three phases previously mentioned using the historical data from 1990 to 2010. The full spatial resolution of the input 


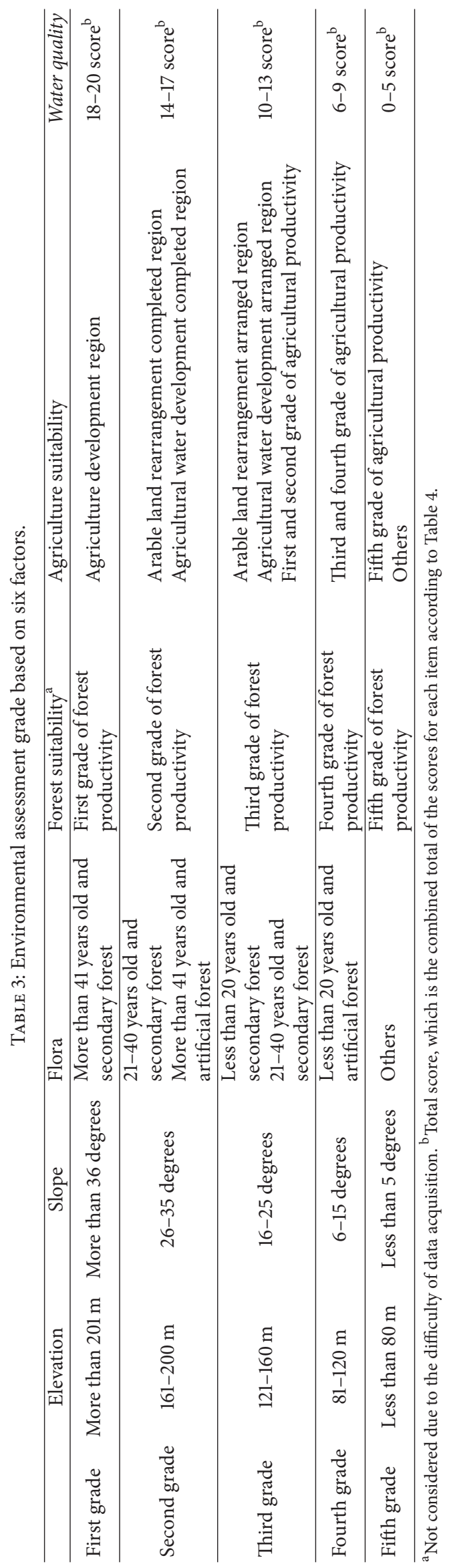




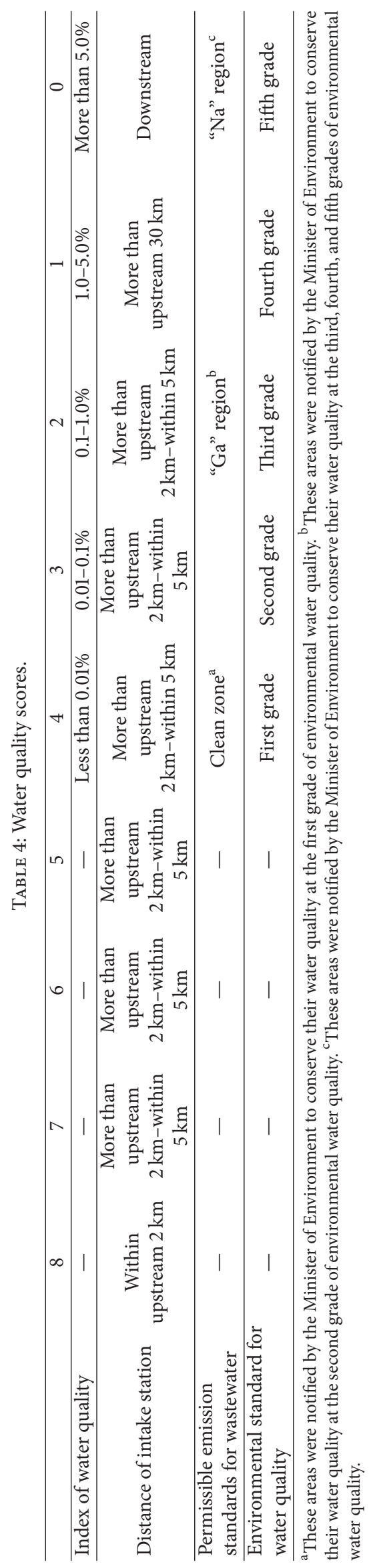


TABLE 5: Selected SLEUTH indices for evaluating the accuracy of the simulated output of the model during the calibration phases.

\begin{tabular}{ll}
\hline Index & Description \\
\hline Product & All scores multiplied together \\
Compare & Modeled population for final year/actual population for final year \\
Pop & $\begin{array}{l}\text { Least squares regression score for modeled urbanization compared to actual } \\
\text { urbanization for control years } \\
\text { Least squares regression score for modeled urban edge count compared to actual } \\
\text { urban edge count for control years } \\
\text { Edges }\end{array}$ \\
Clusters & $\begin{array}{l}\text { Least squares regression score for modeled urban clustering compared to known } \\
\text { urban clustering for control years }\end{array}$ \\
Slope & $\begin{array}{l}\text { Least squares regression of average slope for modeled urbanized cells compared to } \\
\text { average slope of known urban cells for control years }\end{array}$ \\
$X$-mean & $\begin{array}{l}\text { Least squares regression of average } X \text { values for modeled urbanized cells compared } \\
\text { to average } X \text { values of known urban cells for control years }\end{array}$ \\
$Y$-mean & to average $Y$ values of known urban cells for control years
\end{tabular}

Source: Dietzel and Clarke (2007).

TABLE 6: Summary of coefficients during the calibration process.

\begin{tabular}{|c|c|c|c|c|c|c|c|c|}
\hline \multirow{3}{*}{$\begin{array}{l}\text { Growth } \\
\text { coefficient }\end{array}$} & \multirow{2}{*}{\multicolumn{2}{|c|}{$\begin{array}{c}\text { Coarse } \\
\text { Iterations }^{\mathrm{a}}=4 \\
\text { Total number }^{\mathrm{b}}=3125 \\
\text { OSM }^{\mathrm{c}}=0.5466\end{array}$}} & \multirow{2}{*}{\multicolumn{2}{|c|}{$\begin{array}{c}\text { Fine } \\
\text { Iterations }^{\mathrm{a}}=6 \\
\text { Total number }^{\mathrm{b}}=4500 \\
\text { OSM }^{\mathrm{c}}=0.5653\end{array}$}} & \multirow{2}{*}{\multicolumn{2}{|c|}{$\begin{array}{c}\text { Final } \\
\text { Iterations }^{\mathrm{a}}=8 \\
\text { Total number }^{\mathrm{b}}=7776 \\
\text { OSM }^{\mathrm{c}}=0.5736\end{array}$}} & \multirow{3}{*}{$\begin{array}{c}\text { Derived } \\
\text { forecasting } \\
\text { coefficients }\end{array}$} & \multirow{3}{*}{$\begin{array}{l}\text { Best fit } \\
\text { coefficient } \\
\text { values }\end{array}$} \\
\hline & & & & & & & & \\
\hline & Range & Step & Range & Step & Range & Step & & \\
\hline Diffusion & $0-100$ & 25 & $80-100$ & 5 & 95-100 & 1 & 100 & 100 \\
\hline Breed & $0-100$ & 25 & $0-20$ & 5 & $5-10$ & 1 & 6 & 6 \\
\hline Spread & $0-100$ & 25 & $80-100$ & 5 & $80-85$ & 1 & 84 & 84 \\
\hline Slope & $0-100$ & 25 & $50-75$ & 5 & $55-65$ & 2 & 61 & 1 \\
\hline Road gravity & $0-100$ & 25 & $25-50$ & 5 & $25-35$ & 2 & 25 & 49 \\
\hline
\end{tabular}

${ }^{\mathrm{a}}$ Monte Carlo iterations. ${ }^{\mathrm{b}}$ Total number of simulations. ${ }^{\mathrm{c}}$ Top value of optimized SLEUTH metric (OSM).

layers $(100-\mathrm{m})$ was applied in all three calibration phases. Additionally, self-modification parameters, road gravity sensitivity, slope sensitivity, critical low, critical high, boom, and bust were all set to default values.

For the coarse calibration phase, the entire range of coefficient values from 0 to 100 was assigned, with incremental steps of 25 . For the next calibration phase, these were refined to narrower ranges selected from the top five OSM scores. In the fine calibration phase, diffusion, breed, spread, slope resistance, and road gravity parameters covered values of $80-100,0-20,80-100,50-75$, and $25-50$, respectively. These ranges narrowed further to $95-100,5-10,80-85,55-65$, and 25-35, respectively, in the final calibration phase. Each calibration was successful in increasing the OSM value. The final calibration produced an acceptable top OSM value of 0.574 , which compares favorably with other SLEUTH applications. Then, the best coefficient set in 100 Monte Carlo iterations with one-step increments was used to derive an average for each coefficient.

The coefficient values used to predict growth were 100 , $6,84,1$, and 49 for diffusion, breed, spread, slope resistance, and road gravity, respectively. The high value for the diffusion coefficient reflects the high probability of establishing new urban centers through spontaneous growth. The low breed coefficient reflects the low probability of the establishment of new urban centers and is probably a mark of the prior success of the greenbelts in limiting the growth of smaller towns. The low value for slope reflects the fact that the steepest slopes were cut out by the excluded layer. The spread and road gravity coefficients were relatively high. This reflects the high probability of urbanization moving outward from existing urban centers, and infilling. Furthermore, urban growth has been affected by the road network. Finally, the score for slope resistance was so low that it was concluded that topography is not a limiting factor for urban sprawl (Table 6).

4.2. Model Validation. The historical trend-based urban growth profile was simulated using the 1990 to 2010 time period. The accuracy of the simulated results for the 2010 urban layer was evaluated using receiving operating characteristic (ROC) and Kappa statistics. Those pixels forecast to become urban with a probability greater than 0.769 were considered urban for the purposes of validation.

The ROC method is an excellent method to evaluate the validity of a model that predicts the occurrence of an 


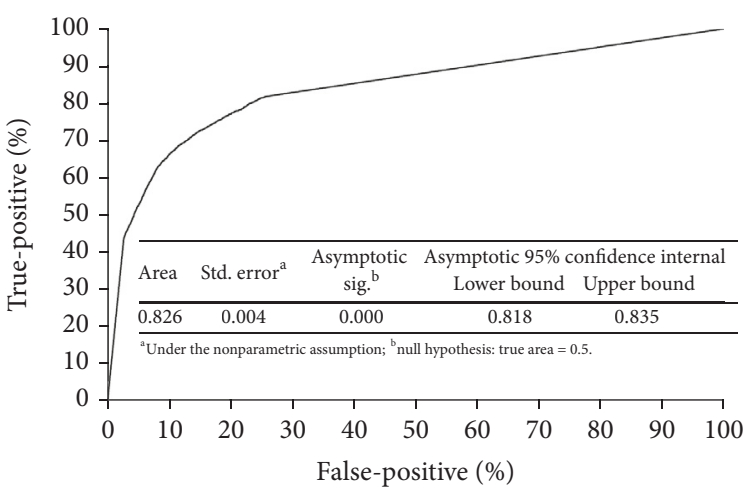

FIGURE 4: Receiver operator characteristic (ROC) curve derived from the cumulative probability of urbanization for the year 2010 and the actual urban area in 2010.

TABLE 7: Contingency table for accuracy analysis of the SLEUTH model.

\begin{tabular}{|c|c|c|c|c|}
\hline \multirow{2}{*}{ Simulated 2010 urban map } & \multicolumn{2}{|c|}{ Classified 2010 urban map } & \multirow{2}{*}{ Total } & \multirow{2}{*}{ Producer accuracy } \\
\hline & Urban & Nonurban & & \\
\hline Urban & 135,494 & 59,445 & 194,939 & 100.0 \\
\hline Nonurban & - & 465,774 & 465,774 & 0.0 \\
\hline Total & 135,494 & 525,219 & 660,713 & - \\
\hline User accuracy & 69.5 & 30.5 & - & - \\
\hline Overall accuracy & - & - & - & 91.0 \\
\hline Kappa statistic & - & - & - & 76.3 \\
\hline
\end{tabular}

event by comparing an image depicting the probability of that event and a binary image showing where that class actually exists, an image created when the simulated and observed maps are overlain [35]. To define the ROC, true-positive and false-positive rates are plotted for every percentile class. The ROC statistic is the area under the curve (AUC), whose value ranges from 0 to 1 . Values between 0.7 and 0.9 show reliable precision, whereas scores higher than 0.9 or lower than 0.7 indicate high or low precision, respectively [36]. Figure 4 presents the ROC curve comparing the cumulative probability image of the year 2010 and the Boolean urban map of the corresponding year. The AUC value was 0.826 , which can be taken as reliable precision.

The Kappa statistic measures the observed agreement between the classification and the reference data and the agreement that might be attained solely by chance matching. Values of the Kappa statistic ranges between 0 (completely inaccurate) and 1 (completely accurate) $[37,38]$. Values lower than 0.4 represent poor or very poor agreement, values from 0.4 to 0.55 represent fair agreement, values from 0.55 to 0.7 represent good agreement, values from 0.7 to 0.85 represent very good agreement, and values higher than 0.85 represent excellent agreement between images [39]. In this study, Kappa statistics were calculated using an error matrix between the simulated Boolean urban map of the year 2010 and the Boolean urban map of the same year. We obtained a value of 0.763 , which can be taken as a very good agreement between the two maps (Table 7). The analysis of accuracy via the ROC and Kappa statistics indicated that the model, as calibrated for the study area, detected growth characteristics successfully during the prior model calibration years.

\subsection{Prediction for Each Scenario}

4.3.1. Future Urban Growth. The outcomes of the model simulations for each scenario are summarized in Table 8 and Figure 5. Scenario 1, which is the maintenance scenario, was limited to development close to the greenbelt. In scenario 1, the expected extent of the urban area in 2020 was $2090 \mathrm{~km}^{2}$, an increase of $54.25 \%$ from 2010 . The decrease in the area of green space, such as farmland, grassland, and forest, was caused by an increase in the urban area. The urban growth mostly occurred to the west of Seoul, likely due to the high altitude and steep gradient east of the research area.

Scenario 2 is the elimination scenario, which represents the elimination of the greenbelt zone completely. Under scenario 2, the city was expected to have an area of $2395 \mathrm{~km}^{2}$ by 2020 , up $76.78 \%$ from 2010 , which suggested relatively rapid urban development. Consequently, the area of green space in 2020 decreased by $75 \%$ compared to 2010 and the decrease accelerated more than scenario 1 . The spatial patterns of the future city were generally similar to those in scenario 1; however, the urban areas around Seoul increased due to the elimination of the greenbelt zone.

Scenario 3 is the managed elimination scenario. The urban area in 2020 was projected to be $2094 \mathrm{~km}^{2}$, a $54.55 \%$ increase, which is slightly more than that of scenario 1 . The area of grassland and forest compared to 2010 decreased 


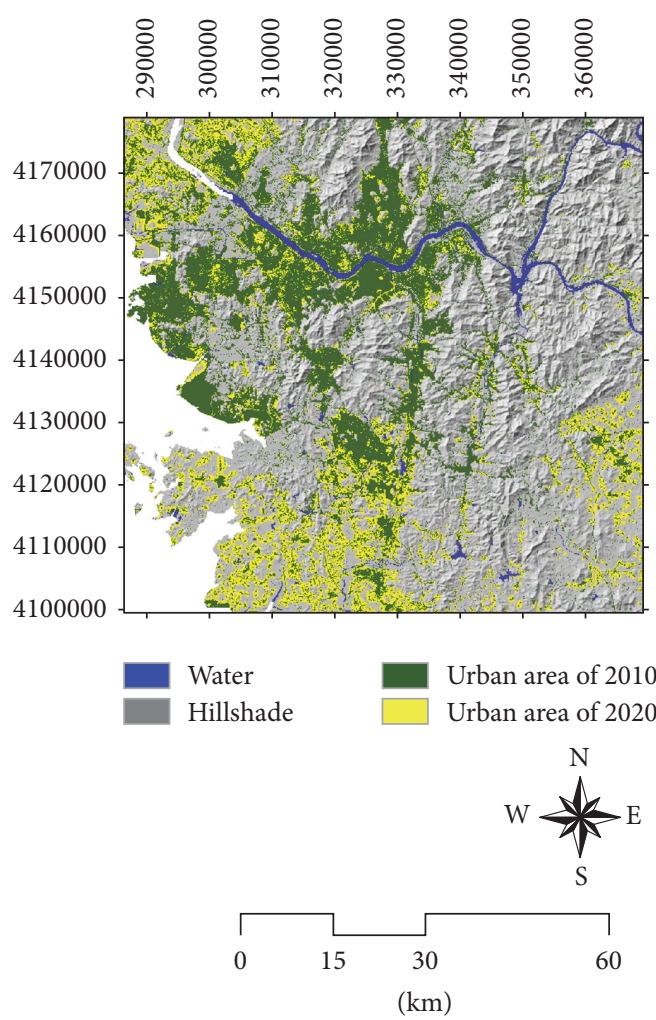

(a)
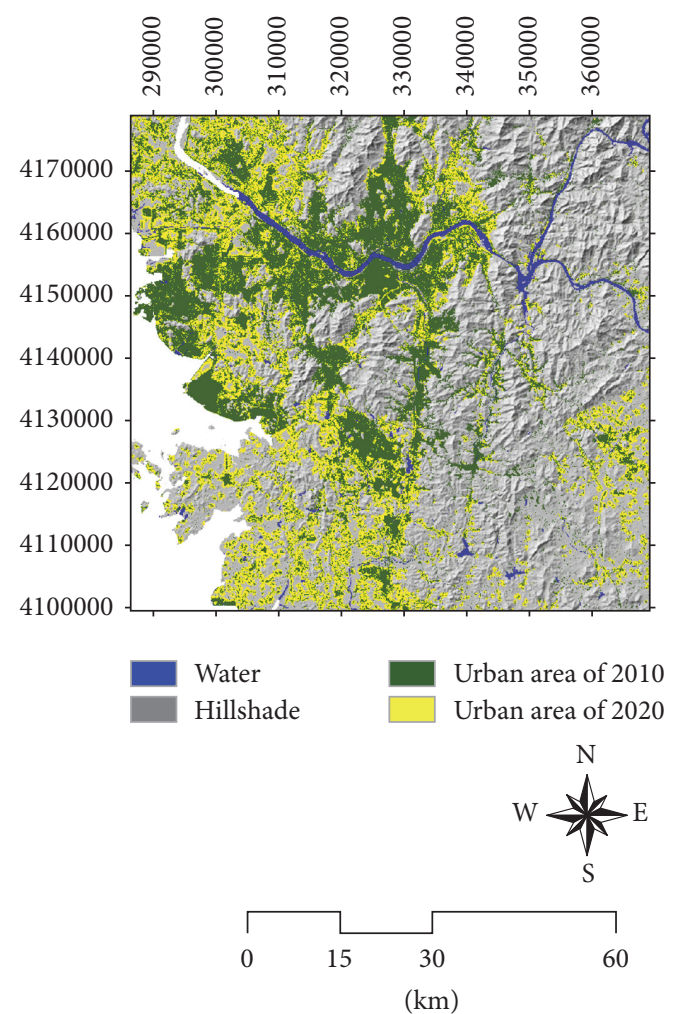

(b)
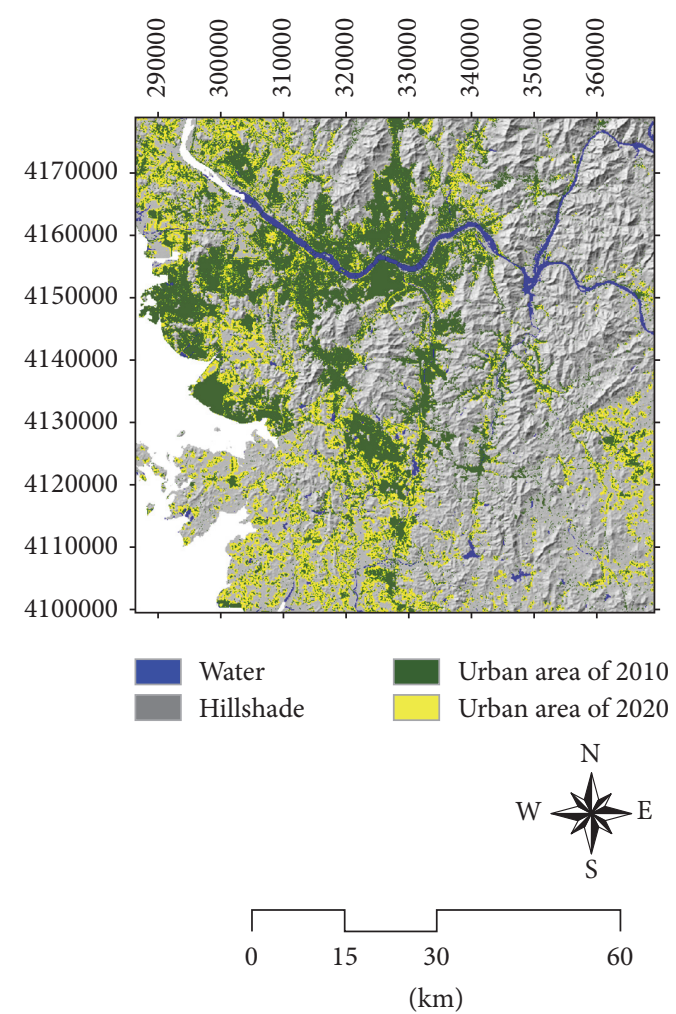

(c)

FIGURE 5: Spatial distribution of the simulated urban areas for each scenario compared to that in 2010: (a) scenario 1, (b) scenario 2, and (c) scenario 3 . 
TABLE 8: Land use classes for each scenario and percentage change in area from 2010 (unit: $\mathrm{km}^{2},\left(\%^{\mathrm{a}}\right)$ ).

\begin{tabular}{lccccccc}
\hline & 2010 & \multicolumn{2}{c}{ Scenario 1 } & \multicolumn{2}{c}{ Scenario 2 } & \multicolumn{2}{c}{ Scenario 3 } \\
\hline Urban & 1,355 & 2,090 & $(54.25)$ & 2,395 & $(76.78)$ & 2,094 & $(54.55)$ \\
Farmland & 1,256 & 1,052 & $(-16.25)$ & 961 & $(-23.49)$ & 1,006 & $(-19.87)$ \\
Grassland & 688 & 500 & $(-27.34)$ & 435 & $(-36.79)$ & 507 & $(-26.35)$ \\
Forest & 2,460 & 2,181 & $(-11.38)$ & 2,052 & $(-16.60)$ & 2,217 & $(-9.91)$ \\
Water & 114 & 114 & $(0.00)$ & 114 & $(0.00)$ & 114 & $(0.00)$ \\
Wetland & 25 & 14 & $(-43.49)$ & 12 & $(-53.30)$ & 15 & $(-38.14)$ \\
Barren & 132 & 80 & $(-39.55)$ & 61 & $(-53.51)$ & 77 & $(-41.63)$ \\
Total & 6,030 & 6,030 & & 6,030 & & 6,030 & \\
\hline
\end{tabular}

${ }^{\text {a Percentage change compared to } 2010 .}$

TABLE 9: Amount of urban area in 2020 for each scenario inside and outside of the greenbelt $\left(\right.$ unit: $\left.^{2} \mathrm{~km}^{2},\left(\%^{\mathrm{a}}\right)\right)$.

\begin{tabular}{|c|c|c|c|c|c|c|c|c|}
\hline \multirow[b]{2}{*}{ Inside greenbelt } & \multicolumn{2}{|c|}{2010} & \multicolumn{2}{|c|}{ Scenario 1} & \multicolumn{2}{|c|}{ Scenario 2} & \multicolumn{2}{|c|}{ Scenario 3} \\
\hline & 606 & $(44.69)$ & 718 & $(34.33)$ & 1,020 & $(42.57)$ & 832 & $(39.72)$ \\
\hline Outside of greenbelt & 749 & $(55.31)$ & 1,372 & $(65.67)$ & 1,376 & $(57.43)$ & 1,262 & $(60.28)$ \\
\hline Total & 1,355 & $(100.00)$ & 2,090 & $(100.00)$ & 2,395 & $(100.00)$ & 2,094 & $(100.00)$ \\
\hline
\end{tabular}

${ }^{\text {a Percentage of total area. }}$

compared with scenario 1 , accounting for $36.3 \%$ of the total. The area of farmland increased by $19.9 \%$, up $3 \%$ from scenario 1. Some areas of farmland in the northeast and the southwest of Seoul were eliminated from the greenbelt zone due to urbanization.

The urban area within the study area will be extended in the future through the decrease of green space. The area of greenspace decreased minimally under scenario 1 but most significantly under scenario 2 . It was clear that the greenbelt zone contributed to ensuring that green space remained around the city. Although the greenbelt zone will be eliminated under organized management, the decrease in the amount of green space is a necessity to secure land for development. In particular, many areas of farmland have decreased due to development. Adequate countermeasures should be prepared to protect and preserve farmland.

4.3.2. Leapfrog Development. The concept of leapfrog development emerged from studies on the spatial evolution of urban areas [40]. Leapfrog development is a discontinuous pattern of urbanization with patches of developed lands that are widely separated from each other and from the boundaries of recognized urbanized areas [41]. The greenbelt zone was subdivided into inside and outside regions, on the basis of the outer boundary line and the urban area, and each scenario was analyzed using these regions (Table 9, Figure 6).

Under scenario 1, the urban area of the inside region was $718 \mathrm{~km}^{2}$, which was the smallest of all the scenarios; while the urban area of the outside region was $1372 \mathrm{~km}^{2}$. In this scenario urban sprawl was avoided due to the greenbelt, and development inside the greenbelt zone was extensive. However, urban development could occur in various locations outside the greenbelt zone, namely, leapfrogging development; in this case, the range of SMA would be expanded.
In scenario 2 , the area of the inside region increased significantly to $1020 \mathrm{~km}^{2}$ by the elimination of the greenbelt zone, with the area of the outside region being $1376 \mathrm{~km}^{2}$. The elimination of the greenbelt caused a sharp increase in the urban area within the outside region as well as the inside region. In addition, the urban area within the inside region increased compared with scenario 1, but the urban area in the outside region decreased slightly under scenario 3. Urban development was concentrated within the inside region and leapfrog development was avoided.

Therefore, leapfrog development could be caused by the presence of a greenbelt, which was not the initial intention of planners. If the greenbelt zone is eliminated by systematic planning and ecofriendly development, urban growth could be controlled effectively.

4.3.3. Conurbation. The development of a conurbation means that an extensive urban area is formed resulting from the expansion of the central city and its urban sprawl, including when these zones merge together. Buffer zones with $10-\mathrm{km}$ intervals were produced on the basis of the urban area in 2010, and the urban areas of each buffer zone were analyzed (Table 10, Figure 7).

In scenario 1, the urban areas within the $20-\mathrm{km}$ buffer zone were $1051 \mathrm{~km}^{2}$ and accounted for $60.1 \%$ of the total urban area. A conurbation was not formed due to the greenbelt zone. A conurbation was formed in the northwest region of the research area under scenario 2 . From the results of scenarios 1 and 2, the greenbelt clearly contributed to the avoidance of the development of conurbations.

In scenario 3, the urban area extended into the area located near Seoul that was eliminated from the greenbelt. As a result, the urban areas within the $20-\mathrm{km}$ buffer zone covered an area of $1120 \mathrm{~km}^{2}$, which was a slight increase compared to scenario 1 . However, areas located within a $5-\mathrm{km}$ radius of 


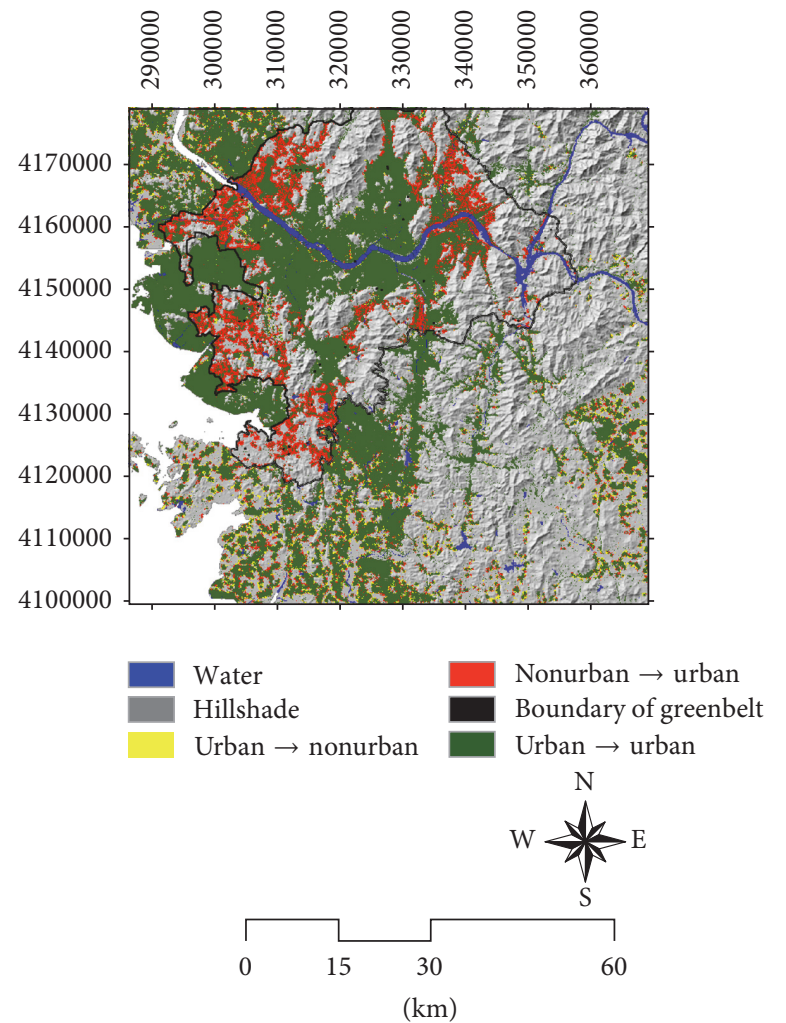

(a)

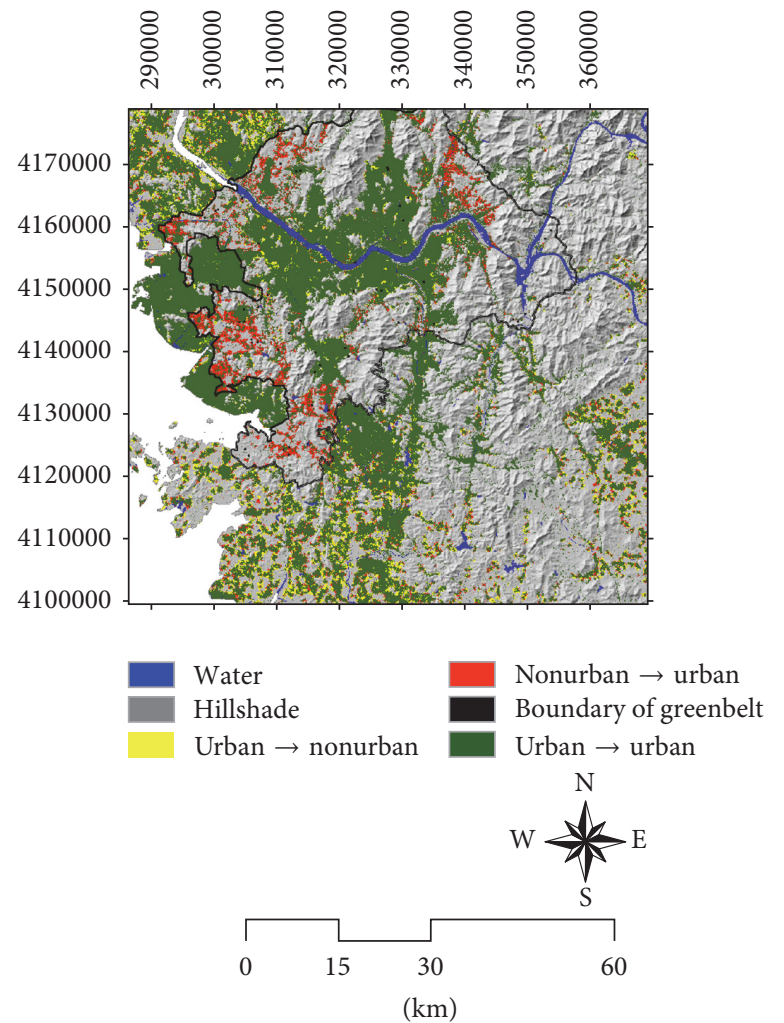

(b)

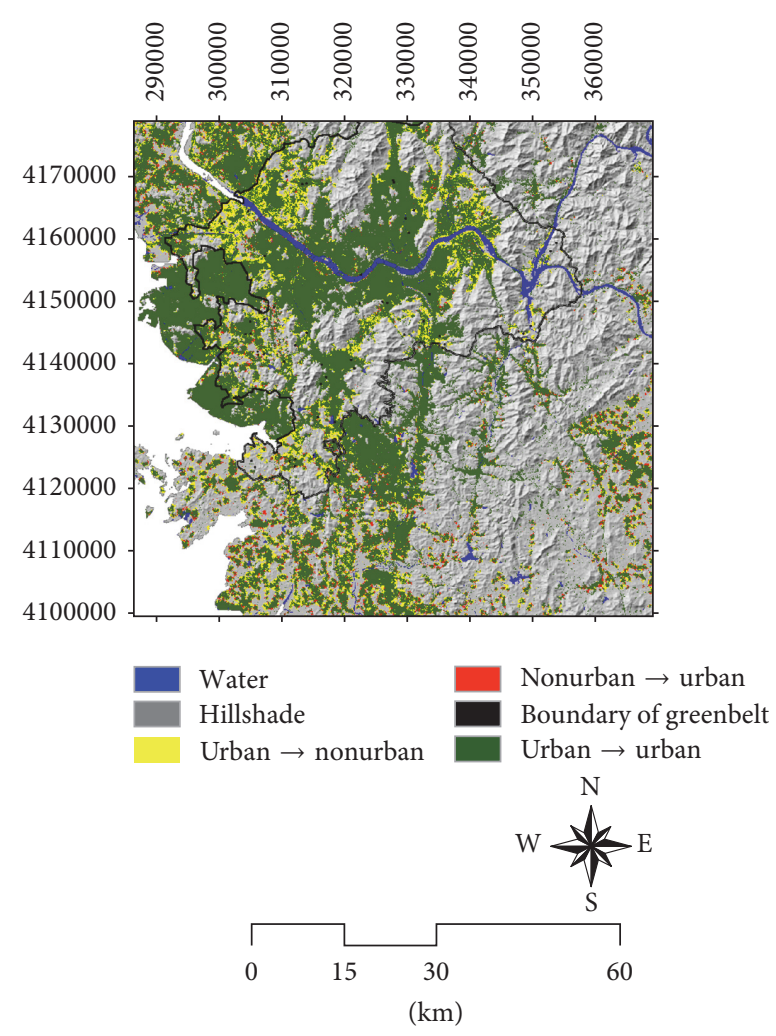

(c)

FIGURE 6: The change in urban areas for each scenario inside and outside of the greenbelt: (a) scenarios 1 and 2, (b) scenarios 1 and 3, and (c) scenarios 2 and 3 . 


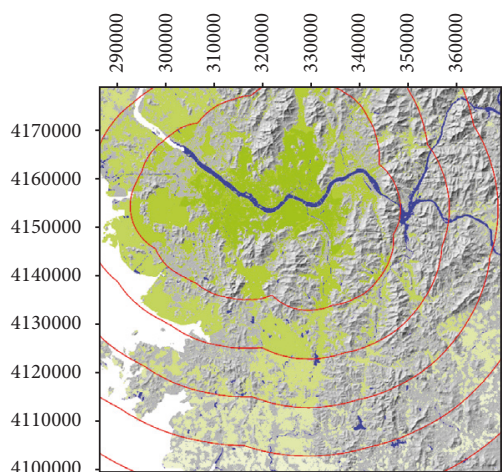

Water

Boundary of buffer zone

Urban areas of Seoul city in 2010

Urban areas of $0-10-\mathrm{km}$ buffer zone in 2020

Urban areas of $10-20-\mathrm{km}$ buffer zone in 2020

Urban areas of 20-30-km buffer zone in 2020

Urban areas of 30-40-km buffer zone in 2020

Urban areas of more than $40 \mathrm{~km}$ buffer zone in 2020

Hillshade

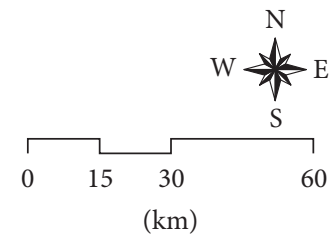

(a)

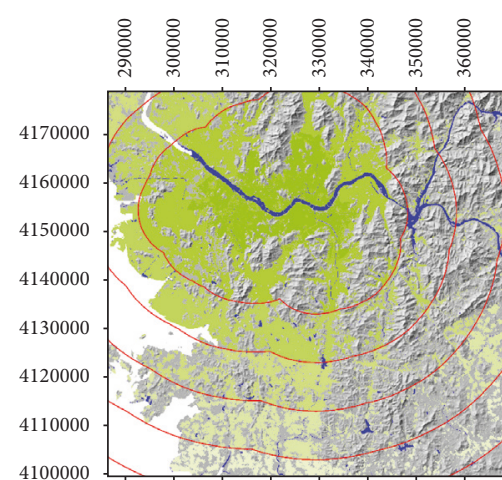

Water

Boundary of buffer zone

Urban areas of Seoul city in 2010

Urban areas of $0-10-\mathrm{km}$ buffer zone in 2020

Urban areas of $10-20-\mathrm{km}$ buffer zone in 2020

Urban areas of 20-30-km buffer zone in 2020

Urban areas of 30-40-km buffer zone in 2020

Urban areas of more than $40 \mathrm{~km}$ buffer zone in 2020

Hillshade

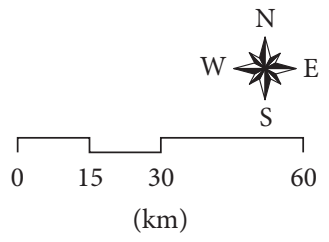

(b)

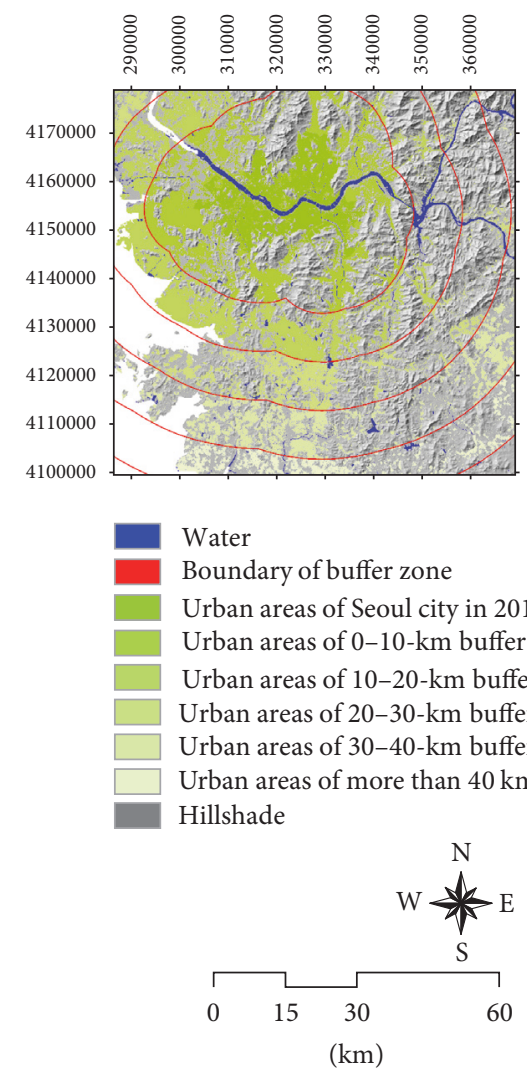

(c)

FiguRE 7: Spatial distribution of the simulated urban areas for each scenario at the buffer zone with 10-km intervals: (a) scenario 1, (b) scenario 2 , and (c) scenario 3. 
TABLE 10: The amount of urban area in 2020 for each scenario in the buffer zone at 10-km intervals (unit: $\mathrm{km}^{2},\left(\%^{\mathrm{a}}\right)$ ).

\begin{tabular}{lcccccccc}
\hline & \multicolumn{2}{c}{2010} & \multicolumn{2}{c}{ Scenario 1 } & \multicolumn{2}{c}{ Scenario 2 } & \multicolumn{2}{c}{ Scenario 3 } \\
\hline $0-10 \mathrm{~km}$ & 369 & $(36.32)$ & 508 & $(29.01)$ & 727 & $(35.39)$ & 570 & $(32.52)$ \\
$10-20 \mathrm{~km}$ & 372 & $(36.60)$ & 543 & $(31.05)$ & 610 & $(29.68)$ & 550 & $(31.35)$ \\
$20-30 \mathrm{~km}$ & 130 & $(12.76)$ & 262 & $(14.97)$ & 282 & $(13.70)$ & 251 & $(14.31)$ \\
$30-40 \mathrm{~km}$ & 100 & $(9.81)$ & 284 & $(16.22)$ & 283 & $(13.76)$ & 251 & $(14.29)$ \\
More than 40 km & 46 & $(4.52)$ & 153 & $(8.74)$ & 153 & $(7.46)$ & 132 & $(7.54)$ \\
Total & 1,017 & $(100.00)$ & 1,749 & $(100.00)$ & 2,055 & $(100.00)$ & 1,754 & $(100.00)$ \\
\hline
\end{tabular}

${ }^{a}$ Percentage of total area.

Seoul were restricted from urban development by the " 2020 Metropolitan City-Region Planning in the National Land Use Planning Law." Due to this law, even though the greenbelt zone would be eliminated, urban growth near Seoul city could be protected. However, the west side of the research area would still have the potential for conurbation development.

\section{Discussion and Conclusion}

The urban growth management policy in South Korea is changing to accommodate environmentally sustainable development, rather than simply the restriction of development in greenbelts, in order to adapt to increasing future development demands. Under such circumstances, the modification and removal of greenbelts has been considered. This research aimed to analyze the impact of the removal of greenbelts on urban growth. Using the SLEUTH model to predict urban growth, three scenarios were established for SMA to analyze the resulting growth and compare the results for each scenario.

To apply the SLEUTH model, urban extent data from 1990, 1995, 2000, and 2010, the road network data from 2000 and 2005, and topographic slopes and hill-shading from 2011 were used as input data. The model was calibrated using historical data from 1990 to 2010. The calibration process was successful according to the best value of OSM in the final calibration, which was 0.574. Additionally, the application of ROC and Kappa statistics resulted in values of 82.6 and $76.3 \%$, respectively, indicating that the SLEUTH model was successful in predicting changes in the research area over the calibration period of 1990-2010.

A comparison of the urban growth under the three scenarios revealed that the green space around the city would remain secure, and a greenbelt zone would prevent urban sprawl and the development of conurbations. However, leapfrog development could be caused by the presence of the greenbelt zone, and urban development in the suburbs of SMA would be accelerated. These phenomena may be accelerated by the complete elimination of the greenbelt zone. The greenbelt zone should therefore be managed to prevent rapid urban growth in the SMA. In addition, part of the urban area increased as a suburb of Seoul and was absorbed into the greenbelt zone, clearly indicating that urban growth would occur near Seoul. These results indicate that urban sprawl and the development of conurbations could be prevented by the elimination of the greenbelt under systematic development planning. Agricultural land faces a higher pressure from urban development, due to the relatively low altitude and gradient. A countermeasure should be prepared to protect and manage farmland sustainably.

The presence of a greenbelt zone could prompt leapfrogging development, which was not the initial intention of planners; this, in turn, would result in the gradual elimination of the greenbelt over the entire country. Thus, the rationale for maintaining a greenbelt is undermined in this situation. Nevertheless, the continued existence and function of the greenbelt zone must be maintained due to the significant damage that urban development would have on the environment and the severe urban problems that would be caused by full elimination of the greenbelt. Therefore, it is advisable to perform greenbelt removal with the intention of maintaining its original goals and function and to mitigate the adverse effects as much as possible. The ecofriendly development of areas removed from the greenbelt will reduce the need for land use management, and improved management can protect the areas that remain in the greenbelt from the increasing development pressure that will arise. Such management could use the principles of smart growth and sustainability planning, perhaps using land trades, mixed land use, and densification.

In addition, an environmental assessment was performed to determine the standard of elimination. A standard environment assessment methodology was established by MLIT in 1999. Some items are difficult to consider using this methodology, because the established laws have changed over time or the standard thematic map is no longer being published. The standard of elimination should be examined thoroughly to develop and manage ecofriendly policies.

The SLEUTH model used in this study has been successfully applied worldwide over the past 15 years to simulate land use change. Using SLEUTH, potential outcomes can be visualized and quantified, model outputs can be closely linked using GIS, and raster-based spatial data derived from remote sensing platforms can be easily incorporated into the model [26]. However, the SLEUTH model only considers road networks as sets of infrastructure parameters. Because urban growth occurs via more complex factors, a greater variety of urban growth factors can reflect various aspects of the real world, such as socioeconomic and physical factors. A study that enhances the SLEUTH model should therefore be conducted through various statistical methods or integration with existing models. 
As a result, the SLEUTH model was able to efficiently model and simulate the forecast scenarios that will follow such policy changes. Furthermore, the results of this study will be useful for the government and planning agencies as a basis for establishing a new urban growth management policy. The application of multiple scenarios in this analysis of the consequences of the future removal of development restrictions should improve the usefulness of these findings [33]. Using such information, South Korea will be able to set policy, successfully perform environmentally sustainable urban development, and achieve sustainable development through a balance between urban growth and environmental conservation.

\section{Disclosure}

This research was conducted while the lead author was on sabbatical at the University of California, Santa Barbara, California, USA.

\section{Conflicts of Interest}

The authors declare that there are no conflicts of interest regarding the publication of this paper.

\section{Acknowledgments}

This work was financially supported by the BK21 Plus Project of the Graduate School of Earth Environmental Hazard Systems and by a National Research Foundation of Korea (NRF) grant funded by the Korean government (MSIP) (no. NRF-2017R1A2B2009033).

\section{References}

[1] C. Rakodi, F. Nunan, and J. D. McCallum, "Sustainable urbanisation-Achieving agenda 21," in Human Settlement Program, p. 32, Geneva, Switzerland, 2002.

[2] P. Street, "Scenario workshops: A participatory approach to sustainable urban living?" Futures, vol. 29, no. 2, pp. 139-158, 1997.

[3] United Nations Secretariat, World urbanization prospects, the 2014 revision, United Nations, The department of economic and social affairs, New York, NY, USA, 2014.

[4] United Nations Secretariat, World population prospects, the 2006 revision, vol. 32, United Nations, The department of economic and social affairs, New York, NY, USA, 2007.

[5] F. Li, X. Liu, D. Hu et al., "Measurement indicators and an evaluation approach for assessing urban sustainable development: a case study for China's Jining City," Landscape and Urban Planning, vol. 90, no. 3-4, pp. 134-142, 2009.

[6] B. A. Portnov and D. Pearlmutter, "Sustainable urban growth in peripheral areas," Progress in Planning, vol. 52, no. 4, pp. 239308, 1999.

[7] T. Yigitcanlar, "Planning for smart urban ecosystems: Information technology applications for capacity building in environmental decision making," Theoretical and Empirical Researches in Urban Management, vol. 3, no. 12, pp. 5-21, 2009.

[8] J. Han, Y. Hayashi, X. Cao, and H. Imura, "Application of an integrated system dynamics and cellular automata model for urban growth assessment: A case study of Shanghai, China," Landscape and Urban Planning, vol. 91, no. 3, pp. 133-141, 2009.

[9] C. J. Dawkins and A. C. Nelson, "Urban containment policies and housing prices: An international comparison with implications for future research," Land Use Policy, vol. 19, no. 1, pp. 1-12, 2002.

[10] Y. Long, Z. Shen, and Q. Mao, "An urban containment planning support system for Beijing," Computers, Environment and Urban Systems, vol. 35, no. 4, pp. 297-307, 2011.

[11] D. N. Bengston and Y. Youn, "Urban Containment Policies and the Protection of Natural Areas: The Case of Seoul's Greenbelt," Ecology and Society, vol. 11, no. 1, Article ID 3, 2006.

[12] M. Yokohari, K. Takeuchi, T. Watanabe, and S. Yokota, "Beyond greenbelts and zoning: A new planning concept for the environment of Asian mega-cities," Landscape and Urban Planning, vol. 47, no. 3-4, pp. 159-171, 2000.

[13] G. Chaudhuri and K. C. Clarke, "The SLEUTH land use change model: A review," International Journal of Environmental Resources Research, vol. 1, no. 1, pp. 88-104, 2013.

[14] D. Stevens, S. Dragicevic, and K. Rothley, "iCity: A GISCA modelling tool for urban planning and decision making," Environmental Modelling and Software, vol. 22, no. 6, pp. 761773, 2007.

[15] B. S. Soares-Filho, G. Coutinho Cerqueira, and C. Lopes Pennachin, "DINAMICA - A stochastic cellular automata model designed to simulate the landscape dynamics in an Amazonian colonization frontier," Ecological Modelling, vol. 154, no. 3, pp. 217-235, 2002.

[16] P. H. Verburg, W. Soepboer, A. Veldkamp, R. Limpiada, V. Espaldon, and S. S. A. Mastura, "Modeling the spatial dynamics of regional land use: The CLUE-S model," Environmental Management, vol. 30, no. 3, pp. 391-405, 2002.

[17] F. Wu, "SimLand: A prototype to simulate land conversion through the integrated GIS and CA with AHP-derived transition rules," International Journal of Geographical Information Science, vol. 12, no. 1, pp. 63-82, 1998.

[18] X. Li and A. Gar-On Yeh, "Modelling sustainable urban development by the integration of constrained cellular automata and GIS," International Journal of Geographical Information Science, vol. 14, no. 2, pp. 131-152, 2000.

[19] K. C. Clarke, S. Hoppen, and L. Gaydos, "A self-modifying cellular automaton model of historical urbanization in the San Francisco Bay area," Environment and Planning B: Planning and Design, vol. 24, no. 2, pp. 247-261, 1997.

[20] C. A. Jantz, S. J. Goetz, D. Donato, and P. Claggett, "Designing and implementing a regional urban modeling system using the SLEUTH cellular urban model," Computers, Environment and Urban Systems, vol. 34, no. 1, pp. 1-16, 2010.

[21] I. Santé, A. M. García, D. Miranda, and R. Crecente, "Cellular automata models for the simulation of real-world urban processes: a review and analysis," Landscape and Urban Planning, vol. 96, no. 2, pp. 108-122, 2010.

[22] Y. Sakieh, B. J. Amiri, A. Danekar, J. Feghhi, and S. Dezhkam, "Simulating urban expansion and scenario prediction using a cellular automata urban growth model, SLEUTH, through a case study of Karaj City, Iran," Journal of Housing and the Built Environment, vol. 30, no. 4, pp. 591-611, 2014.

[23] J. Kim and S. Park, "Simulating the impacts of the greenbelt policy reform on sustainable urban growth: The case of busan metropolitan area," Journal of the Korean Society of Surveying, Geodesy, Photogrammetry and Cartography, vol. 33, no. 3, pp. 193-202, 2015. 
[24] U. Park, J. Heo, T. Oh, I. Lee, and D. Park, Urbanization and urban policies in Korea, vol. 10, Korea Research Institute for Human Settlements, Gyeonggi-do, South Korea, 2010.

[25] R. Rafiee, A. S. Mahiny, N. Khorasani, A. A. Darvishsefat, and A. Danekar, "Simulating urban growth in Mashad City, Iran through the SLEUTH model (UGM)," Cities, vol. 26, no. 1, pp. 19-26, 2009.

[26] C. A. Jantz, S. J. Goetz, and M. K. Shelley, "Using the SLEUTH urban growth model to simulate the impacts of future policy scenarios on urban land use in the Baltimore-Washington metropolitan area," Environment and Planning B: Planning and Design, vol. 31, no. 2, pp. 251-271, 2004.

[27] C. Jantz, S. Drzyzga, and M. Maret, "Calibrating and Validating a Simulation Model to Identify Drivers of Urban Land Cover Change in the Baltimore, MD Metropolitan Region," Land, vol. 3, no. 3, pp. 1158-1179, 2014.

[28] L. Hua, L. Tang, S. Cui, and K. Yin, "Simulating urban growth using the SLEUTH model in a coastal peri-urban district in China," Sustainability (Switzerland), vol. 6, no. 6, pp. 3899-3914, 2014.

[29] C. Dietzel and K. C. Clarke, "Toward optimal calibration of the SLEUTH land use change model," Transactions in GIS, vol. 11, no. 1, pp. 29-45, 2007.

[30] E. A. Silva and K. C. Clarke, "Calibration of the SLEUTH urban growth model for Lisbon and Porto, Portugal," Computers, Environment and Urban Systems, vol. 26, no. 6, pp. 525-552, 2002.

[31] C. Dietzel and K. Clarke, "The effect of disaggregating land use categories in cellular automata during model calibration and forecasting," Computers, Environment and Urban Systems, vol. 30, no. 1, pp. 78-101, 2006.

[32] S. Dezhkam, B. J. Amiri, A. A. Darvishsefat, and Y. Sakieh, "Simulating the urban growth dimensions and scenario prediction through sleuth model: a case study of Rasht County, Guilan, Iran," GeoJournal, vol. 79, no. 5, 2014.

[33] W.-N. Xiang and K. C. Clarke, "The use of scenarios in land-use planning," Environment and Planning B: Planning and Design, vol. 30, no. 6, pp. 885-909, 2003.

[34] E. Koomen, P. Rietveld, and T. Nijs, "Modelling land-use change for spatial planning support," Annals of Regional Science, vol. 42, no. 1, pp. 1-10, 2008.

[35] A. Tayyebi, M. R. Delavar, M. J. Yazdanpanah, B. C. Pijanowski, S. Saeedi, and A. H. Tayyebi, "A spatial logistic regression model for simulating land use patterns: A case study of the shiraz metropolitan area of Iran," Advances in Earth Observation of Global Change, pp. 27-42, 2010.

[36] X. Wu, Y. Hu, H. S. He, R. Bu, J. Onsted, and F. Xi, "Performance evaluation of the SLEUTH model in the shenyang metropolitan area of Northeastern China," Environmental Modeling and Assessment, vol. 14, no. 2, pp. 221-230, 2009.

[37] J. R. Jensen, in Introductory Digital Image Processing: A Remote Sensing Perspective, p. 525, Prentice Hall, Upper Saddle River, NY, USA, 3rd edition, 2005.

[38] S. Jayakumar, A. Ramachandran, G. Bhaskaran, J. Heo, and W. S. Kim, "Site Suitability Assessment for Joint Forest Management (JFM)-a Geospatial Approach," Korean Journal of Remote Sensing, vol. 23, no. 5, pp. 473-481, 2007.

[39] R. A. Monserud and R. Leemans, "Comparing global vegetation maps with the Kappa statistic," Ecological Modelling, vol. 62, no. 4, pp. 275-293, 1992.
[40] L. Benguigui, D. Czamanski, and M. Marinov, "City growth as a leap-frogging process: An application to the Tel-Aviv metropolis," Urban Studies, vol. 38, no. 10, pp. 1819-1839, 2001.

[41] R. O. Harvey and W. A. Clark, "The nature and economics of urban sprawl," Land Economics, vol. 41, no. 1, pp. 1-9, 1965. 


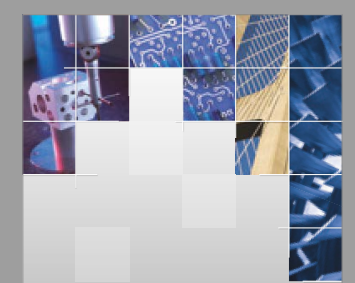

\section{Enfincering}
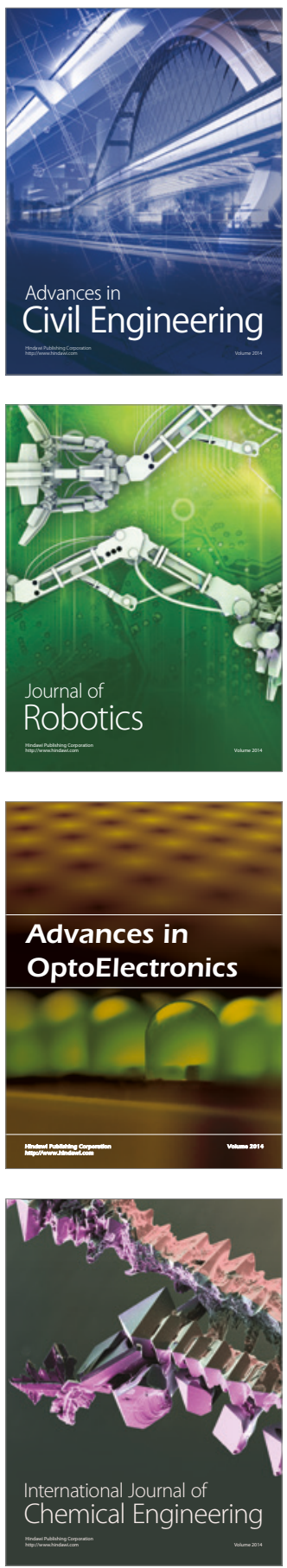

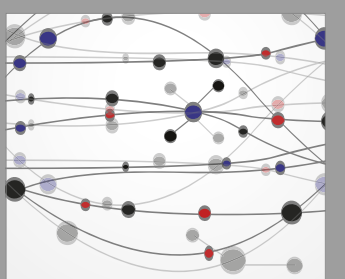

The Scientific World Journal

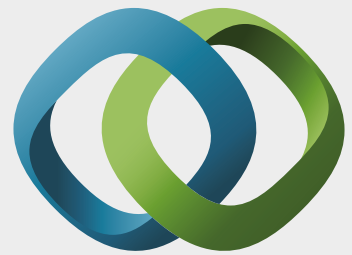

\section{Hindawi}

Submit your manuscripts at

https://www.hindawi.com
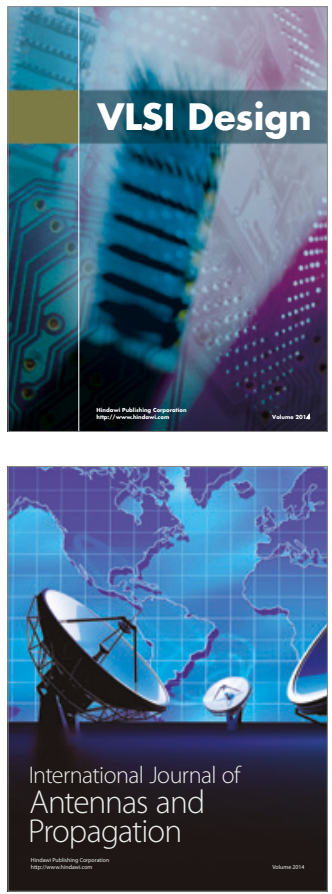

\section{Rotating}

Machinery
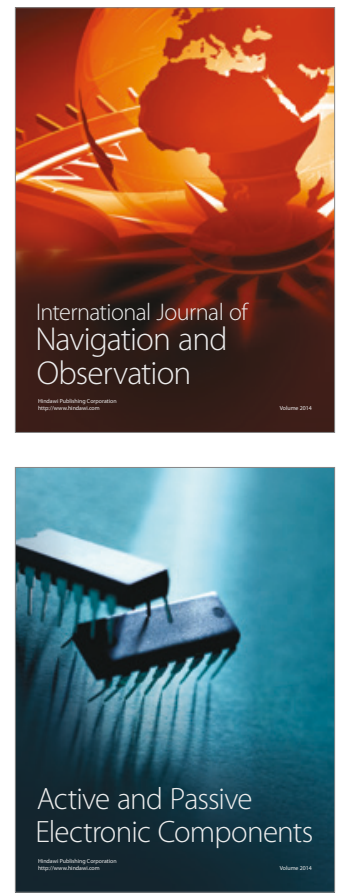
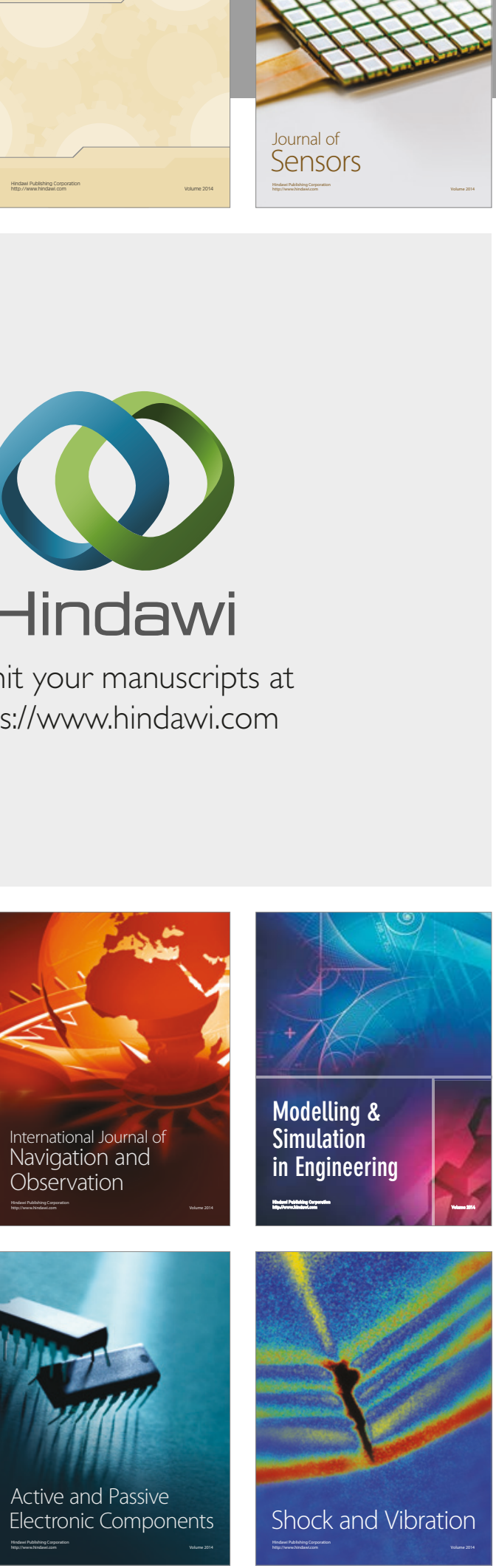
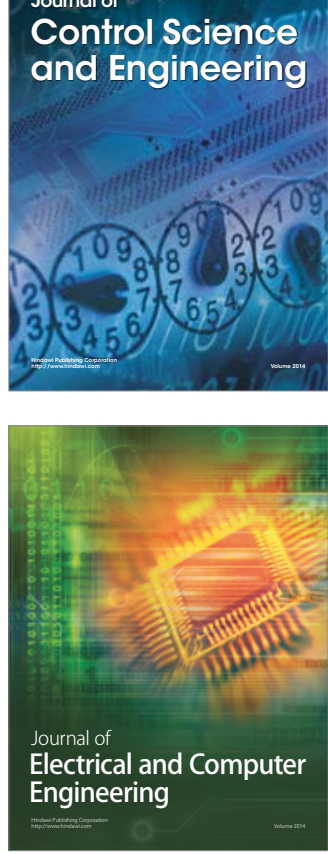

Distributed

Journal of

Control Science

and Engineering
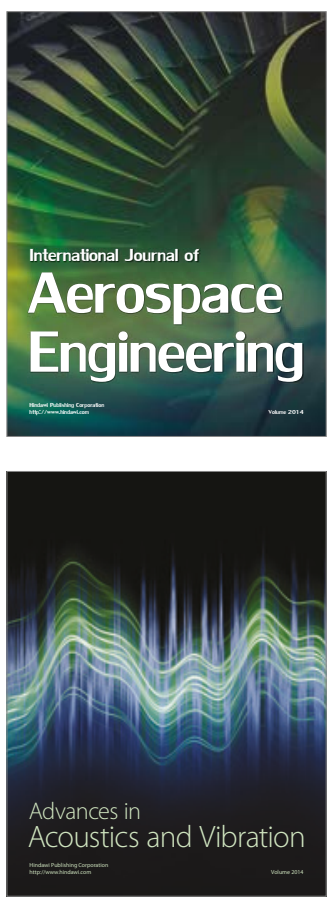

Sensor Networks 